BMJ Open

Diabetes

Research

\& Care

\section{Higher circulating orosomucoid, an acute-phase protein, and reduced glucose-induced insulin secretion in middle-aged Japanese people with prediabetes}

To cite: Tsuboi A, Kitaoka $\mathrm{K}$ Yano $\mathrm{M}$, et al. Higher circulating orosomucoid, an acute-phase protein, and reduced glucoseinduced insulin secretion in middle-aged Japanese people with prediabetes. BMJ Open Diab Res Care 2020;8:e001392. doi:10.1136/ bmjdrc-2020-001392

- Supplemental material is published online only. To view, please visit the journal online (http://dx.doi.org/10.1136/ bmjdrc-2020-001392).

Received 22 March 2020 Revised 19 September 2020 Accepted 28 September 2020

Check for updates

(c) Author(s) (or their employer(s)) 2020. Re-use permitted under CC BY-NC. No commercial re-use. See rights and permissions. Published by BMJ.

For numbered affiliations see end of article.

Correspondence to Dr Tsutomu Kazumi; kazumi@mukogawa-u.ac.jp

\section{ABSTRACT}

Introduction Circulating orosomucoid, an acute-phase protein, predicted type 2 diabetes mellitus risk in several Western countries. Here, we assessed serum orosomucoid (ORM) in relation to prediabetes in the Japanese.

Research design and methods Participants consisted of 83 middle-aged Japanese subjects with normal glucose tolerance (NGT), 37 with prediabetes and 4 with newly identified diabetes, whose homeostasis model assessment-insulin resistance (HOMA-IR) averaged 1.1 $\pm 0.7,1.4 \pm 0.9$ and $1.7 \pm 0.8$, respectively. Body composition, serum inflammatory markers, adiponectin, $\beta$-cell function and insulin resistance inferred from serum insulin kinetics during an oral glucose tolerance test were compared cross-sectionally between those with prediabetes and NGT.

Results Serum orosomucoid, but not high-sensitivity C reactive protein, was elevated in prediabetes $(190 \pm 29$ vs $141 \pm 31 \mathrm{mg} / \mathrm{dL})$ with further elevation in diabetes $(295 \pm 52 \mathrm{mg} /$ $\mathrm{dL})($ all $p<0.001)$. Prediabetes was associated with lower Oral Disposition Index (the product of the Insulinogenic Index and Matsuda Index) with further depression in diabetes. No association was found with skeletal muscle mass, HOMA-IR, serum triglyceride, high-density lipoprotein (HDL) cholesterol and adiponectin.

Conclusions Higher circulating ORM and reduced glucose induced insulin secretion were found in middle-aged Japanese people with prediabetes in the absence of insulin resistance.

\section{INTRODUCTION}

Chronic low-grade inflammation can contribute to the pathogenesis of many diseases including type 2 diabetes and cardiovascular disease. ${ }^{12}$ Prediabetes is a well-known risk factor for type 2 diabetes and has been reported to be associated with cardiovascular disease. ${ }^{34}$ Elevated concentrations of $\mathrm{C}$ reactive protein (CRP), a prime acute-phase protein, were found in people with prediabetes. $^{5-9}$ Associations between CRP and increased risk of developing type 2 diabetes

\section{Significance of this study}

What is already known about this subject?

- Although studies are missing in the Japanese, population studies in Western countries have shown the association between orosomucoid, one of the major acute-phase proteins of glycoprotein acetyls (GlycAs), and type 2 diabetes and between GlycAs and an increase in glycemia and a decrease in insulin secretion.

What are the new findings?

- Japanese people aged 50 years with prediabetes had higher circulating orosomucoid, reduced glucose induced insulin secretion and insulin resistance which is indistinguishable from that in normal glucose tolerance.

How might these results change the focus of research or clinical practice?

- Elevated orosomucoid may be related to reduced glucose induced insulin secretion in middle-aged Japanese people with prediabetes.

were demonstrated in studies including those from East Asia. ${ }^{10-14}$

Orosomucoid (ORM), also known as $\alpha-1$ acid glycoprotein, is another acute-phase protein and is produced by liver and peripheral tissues in response to systemic reaction to inflammation..$^{15}$ In addition to acting as an acute-phase reactant and disease marker, ORM has many activities including modulating immunity, binding and carrying drugs, maintaining the barrier function of capillary, and mediating the sphingolipid metabolism. ${ }^{15}$ Studies conducted in US or European populations have shown that ORM is associated with increased risk of developing type 2 diabetes. ${ }^{13}$ 16-18 Associations between 
circulating ORM and glycemia during an oral glucose tolerance test (OGTT) have previously demonstrated in middle-aged Finnish people. ${ }^{19}$ We found similar associations in young Japanese women and their middle-aged parents. ${ }^{20}{ }^{21}$ However, studies on the relation between ORM and prediabetes are limited as discussed later. Here we evaluated the relation between ORM and prediabetes in middle-aged Japanese people.

\section{METHODS}

We cross-sectionally studied 65 premenopausal middleaged women and 59 middle-aged men, whose details have been reported elsewhere. ${ }^{21} 22$ They were Japanese and biological parents of students of Mukogawa Women's University. Subjects who reported that they were under treatment for clinically diagnosed acute or chronic inflammatory diseases, endocrine, cardiovascular, hepatic, renal diseases, hormonal contraception, and unusual dietary habits were excluded. Nobody reported receiving any medications or having regular supplements. The study was in accordance with the Declaration of Helsinki. All subjects were recruited as volunteers and gave written consent after the experimental procedure had been explained.

After a 12-hour overnight fast, at 8:30, they underwent a standard $75 \mathrm{~g}$ OGTT with measurement of glucose and insulin at 0 min (fasting), $30 \mathrm{~min}, 1$ hour, and 2 hours after glucose ingestion. Prediabetes (impaired fasting glucose (IFG) and/or impaired glucose tolerance (IGT)) and diabetes were diagnosed based on glycemia criteria (fasting and 2-hour glucose concentrations) of the American Diabetes Association. ${ }^{23}$ OGTT revealed prediabetes in 14 women and 23 men, and newly identified diabetes in 4 men. Among 37 subjects with prediabetes, 12 had isolated IFG, 14 isolated IGT and 11 IFG/IGT.

Plasma glucose (PG), hemoglobin A1c (HbA1c), serum insulin, triglyceride, high-density lipoprotein (HDL) cholesterol, adiponectin, leptin, high-sensitivity CRP (hsCRP) and tumor necrosis factor- $\alpha$ (TNF- $\alpha$ ) were measured as previously reported. ${ }^{24}$ ORM concentrations were measured in fasted samples by an immunoturbidimetric method using a commercially available kit ( $\mathrm{N}$ Antiserum to Human $\alpha 1$-acid Glycoprotein, Siemens Healthcare Diagnostics, Tokyo, Japan) and an autoanalyzer (JCA-BM6010, JEOL, Tokyo, Japan). Intra-assay and interassay coefficients of variation at $87 \mathrm{mg} / \mathrm{dL}$ were $1.4 \%$ and $1.7 \%$, respectively. The area under the concentration curves of PG and insulin (AUCg and AUCi, respectively) were calculated by the trapezoid method. Homeostasis model assessment-insulin resistance (HOMA-IR), the Matsuda Index and the Insulinogenic Index (IGI) were calculated as previously reported. ${ }^{25-27}$ The Oral Disposition Index (ODI) was calculated as the product of IGI and Matsuda Index.

Fat mass, bone mass and lean mass for arms, legs, trunk and the total body were measured using whole-body dualenergy X-ray absorptiometry (DXA) (Hologic QDR-2000, software V.7.20D, Waltham, Massachusetts, USA) as previously reported. ${ }^{24}$ The leg region included the entire hip, thigh and leg. General adiposity was assessed using body mass index (BMI), the percentage of body fat (\% body fat) and Fat Mass Index (FMI), the last of which was calculated as body fat mass in kilograms divided by height in square meters. Abdominal fat accumulation was assessed by waist circumference and the ratio of trunk to leg fat. ${ }^{28}$ Skeletal muscle mass was assessed using appendicular Skeletal Muscle Mass Index (SMI) calculated as lean mass in extremities in kilograms dividing by height in square meters.

Data were presented as mean $\pm \mathrm{SD}$ unless otherwise stated. Due to deviation from normal distribution, IGI and ODI were logarithmically transformed for analyses. Comparisons between two groups were made with two-sample t-test. Differences among three groups were analyzed using analysis of variance and then Bonferroni's multiple comparison procedure. Although there were gender differences in associations between body composition and cardiometabolic risk factors, ${ }^{22}$ middle-aged men and women did not differ in ORM and glycemia and insulinemia during OGTT (online supplemental tables 1 and 2), therefore, two groups were combined for analyses. Correlations between ORM and glycemic and other variables were investigated by Pearson's analysis. Stepwise multivariate linear regression analyses were performed to identify most important determinants of ORM. Independent variables included were all variables that showed a significant association with ORM. Because of multicollinearity, glucose values at four time points and $\mathrm{AUCg}$ were analyzed in separate models. A two-tailed value of $\mathrm{p}<0.05$ was considered statistically significant. Statistics were performed with SPSS system V.17.0 (SPSS, Chicago, Illinois, USA).

\section{RESULTS}

Although BMI and waist circumference were higher in women with prediabetes compared with normal glucose tolerance (NGT) (online supplemental table 1), women with prediabetes had a mean BMI $<25.0 \mathrm{~kg} / \mathrm{m}^{2}$ (a cut-off value of obesity) and their waist circumference was far below a cut-off value of abdominal fat accumulation for Japanese women $(<90 \mathrm{~cm})$. However, men in three groups had mean waist circumference $>85 \mathrm{~cm}$ (a cut-off value of abdominal fat accumulation for Japanese men) although BMI averaged $<25.0 \mathrm{~kg} / \mathrm{m}^{2}$ even in men with prediabetes and diabetes (online supplemental table 2). Their mean HOMA-IR ranged from 1.1 to 1.7 (table 1). Women with prediabetes had higher FMI, \% body fat, trunk/leg fat ratio as well.

In spite of highly significant differences in glucose concentrations at four time points during OGTT (all $\mathrm{p}<0.001$ ) (figure 1), there was no significant difference in insulin concentrations at four time points. Although $30 \mathrm{~min}$ insulin concentrations and Matsuda Index (table 1) showed a stepwise decrease from NGT 
Table 1 Anthropometric and biochemical characteristics of middle-aged Japanese people with normal glucose tolerance (NGT), prediabetes and newly identified type 2 diabetes (DM)

\begin{tabular}{|c|c|c|c|c|}
\hline & NGT & Prediabetes & DM & \\
\hline & $n=83$ & $\mathrm{n}=37$ & $n=4$ & * \\
\hline Age (years) & $49.4 \pm 4.3$ & $52.2 \pm 4.2$ & $50.0 \pm 0.8$ & $\dagger$ \\
\hline BMI $\left(\mathrm{kg} / \mathrm{m}^{2}\right)$ & $22.6 \pm 4.9$ & $23.5 \pm 2.8$ & $22.8 \pm 1.5$ & \\
\hline $\mathrm{FMI}\left(\mathrm{kg} / \mathrm{m}^{2}\right)$ & $5.88 \pm 1.94$ & $6.43 \pm 2.59$ & $4.19 \pm 2.24$ & \\
\hline$\%$ body fat (\%) & $26.4 \pm 6.6$ & $27.0 \pm 8.9$ & $18.4 \pm 9.1$ & \\
\hline Waist circumference $(\mathrm{cm})$ & $79.9 \pm 8.3$ & $85.4 \pm 7.6$ & $85.3 \pm 5.8$ & $\dagger$ \\
\hline Trunk/leg fat ratio & $1.88 \pm 0.62$ & $2.23 \pm 0.60$ & $2.60 \pm 0.34$ & $\dagger$ \\
\hline $\mathrm{SMI}\left(\mathrm{kg} / \mathrm{m}^{2}\right)$ & $6.64 \pm 1.05$ & $7.01 \pm 1.04$ & $7.78 \pm 0.46$ & \\
\hline Fasting glucose (mg/dL) & $88 \pm 7$ & $100 \pm 9$ & $130 \pm 38$ & $\dagger \ddagger \S$ \\
\hline $30 \mathrm{~min}$ glucose $(\mathrm{mg} / \mathrm{dL})$ & $130 \pm 27$ & $167 \pm 23$ & $218 \pm 45$ & $\dagger \ddagger \S$ \\
\hline 1 hour glucose (mg/dL) & $126 \pm 36$ & $183 \pm 35$ & $291 \pm 47$ & $\dagger \ddagger \S$ \\
\hline 2 hour glucose $(\mathrm{mg} / \mathrm{dL})$ & $103 \pm 18$ & $145 \pm 29$ & $241 \pm 104$ & $\dagger \ddagger \S$ \\
\hline Fasting insulin $(\mu \mathrm{U} / \mathrm{mL})$ & $5.0 \pm 3.2$ & $5.5 \pm 3.5$ & $6.0 \pm 3.8$ & \\
\hline $30 \mathrm{~min}$ insulin $(\mu \mathrm{U} / \mathrm{mL})$ & $42 \pm 29$ & $31 \pm 20$ & $19 \pm 14$ & \\
\hline 1 hour insulin $(\mu \mathrm{U} / \mathrm{mL})$ & $49 \pm 62$ & $48 \pm 33$ & $45 \pm 30$ & \\
\hline 2 hour insulin $(\mu \mathrm{U} / \mathrm{mL})$ & $35 \pm 30$ & $50 \pm 34$ & $38 \pm 30$ & $\dagger$ \\
\hline $\mathrm{HbA1c}(\%)$ & $5.4 \pm 0.3$ & $5.6 \pm 0.3$ & $6.5 \pm 0.8$ & $\dagger \ddagger \S$ \\
\hline HOMA-IR & $1.1 \pm 0.8$ & $1.4 \pm 0.9$ & $1.7 \pm 0.8$ & \\
\hline Matsuda Index & $11.8 \pm 6.8$ & $9.6 \pm 6.3$ & $6.2 \pm 2.9$ & \\
\hline Insulinogenic Index & $1.4 \pm 2.1$ & $0.4 \pm 0.3$ & $0.2 \pm 0.1$ & $\dagger \ddagger$ \\
\hline $\begin{array}{l}\text { Oral } \\
\text { Disposition Index }\end{array}$ & $15.4 \pm 28.8$ & $3.6 \pm 5.5$ & $0.7 \pm 0.4$ & $\dagger \ddagger \S$ \\
\hline AUCg (mg/dL, 2 hours) & $233 \pm 41$ & $318 \pm 42$ & $480 \pm 104$ & $\dagger \ddagger \S$ \\
\hline AUCi ( $\mu \mathrm{U} / \mathrm{mL}, 2$ hours) & $77 \pm 71$ & $77 \pm 48$ & $64 \pm 42$ & \\
\hline Triglyceride (mg/dL) & $113 \pm 126$ & $99 \pm 53$ & $196 \pm 213$ & \\
\hline HDL cholesterol (mg/dL) & $70 \pm 18$ & $63 \pm 13$ & $63 \pm 24$ & \\
\hline Leptin (ng/mL) & $5.1 \pm 3.3$ & $5.7 \pm 4.1$ & $3.2 \pm 2.6$ & \\
\hline Adiponectin (mg/L) & $9.8 \pm 5.4$ & $8.3 \pm 3.8$ & $5.0 \pm 3.2$ & \\
\hline hsCRP $(\mu \mathrm{g} / \mathrm{dL})$ & $28 \pm 77$ & $30 \pm 51$ & $17 \pm 22$ & \\
\hline TNF- $\alpha(p g / m L)$ & $0.7 \pm 0.3$ & $0.7 \pm 0.3$ & $0.6 \pm 0.1$ & \\
\hline
\end{tabular}

Mean \pm SD

${ }^{*} \mathrm{p}<0.05$ or less by Bonferroni's multiple comparison procedures †NGT versus preDM

‡NGT versus DM

§preDM versus DM

AUCg and $\mathrm{AUCi}$, area under the concentration curve of plasma glucose and serum insulin, respectively; BMI, body mass index; FMI, Fat Mass Index; HbA1c, hemoglobin A1c; HDL, high-density lipoprotein; HOMA-IR, homeostasis model assessment-insulin resistance; hsCRP, high-sensitivity $\mathrm{C}$ reactive protein; SMI, Skeletal Muscle Mass Index; TNF- $\alpha$, tumor necrosis factor- $\alpha$.

to diabetes, these changes were not statistically significant. Those with prediabetes and diabetes had lower IGI than those with NGT. ODI decreased in prediabetes as compared with NGT with further decrease in diabetes. AUCg and HbAlc showed stepwise increase from NGT to diabetes whereas AUCi did not differ. Serum ORM showed a stepwise increase (figure 2) whereas SMI, HOMA-IR, serum triglyceride, HDL cholesterol, adiponectin, leptin, TNF- $\alpha$ and hsCRP did not differ.
Although the sample size of prediabetes was small, we compared isolated IFG $(n=12)$ and IGT with and without IFG (IGT group, n=25) (online supplemental table 3). The IGT group had elevated AUCg (334 \pm 38 vs $285 \pm 30 \mathrm{mg} / \mathrm{dL} / 2$ hours, $\mathrm{p}<0.001)$ and serum ORM (196 \pm 29 vs $177 \pm 24 \mathrm{mg} / \mathrm{dL}, \mathrm{p}=0.05)$.

Serum ORM showed strong and positive associations with fasting PG $(\mathrm{r}=0.683, \mathrm{p}<0.001)$ and postload glycemia and AUCg ( $r=0.759-0.961)$ (figure 3 and online 


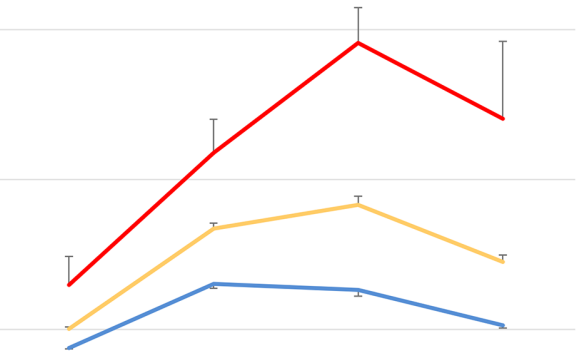

0

0

\section{(mg/dL) \\ Glucose}

400

300

200

100
( $\mu \mathrm{U} / \mathrm{mL})$

60

Insulin

20

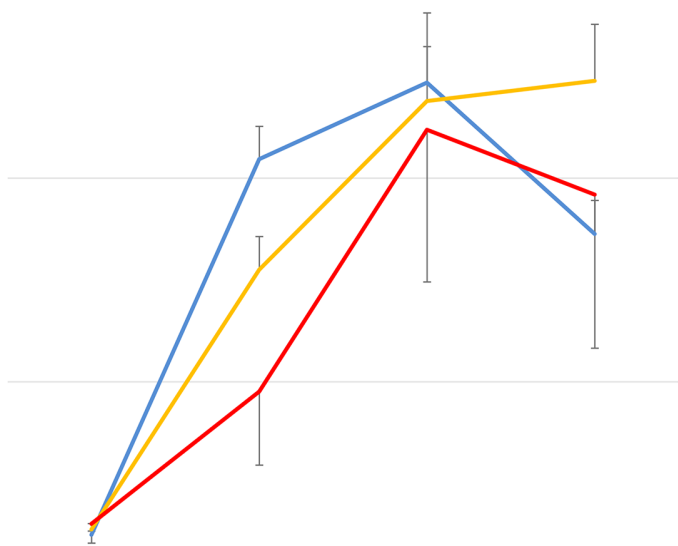

0

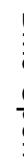



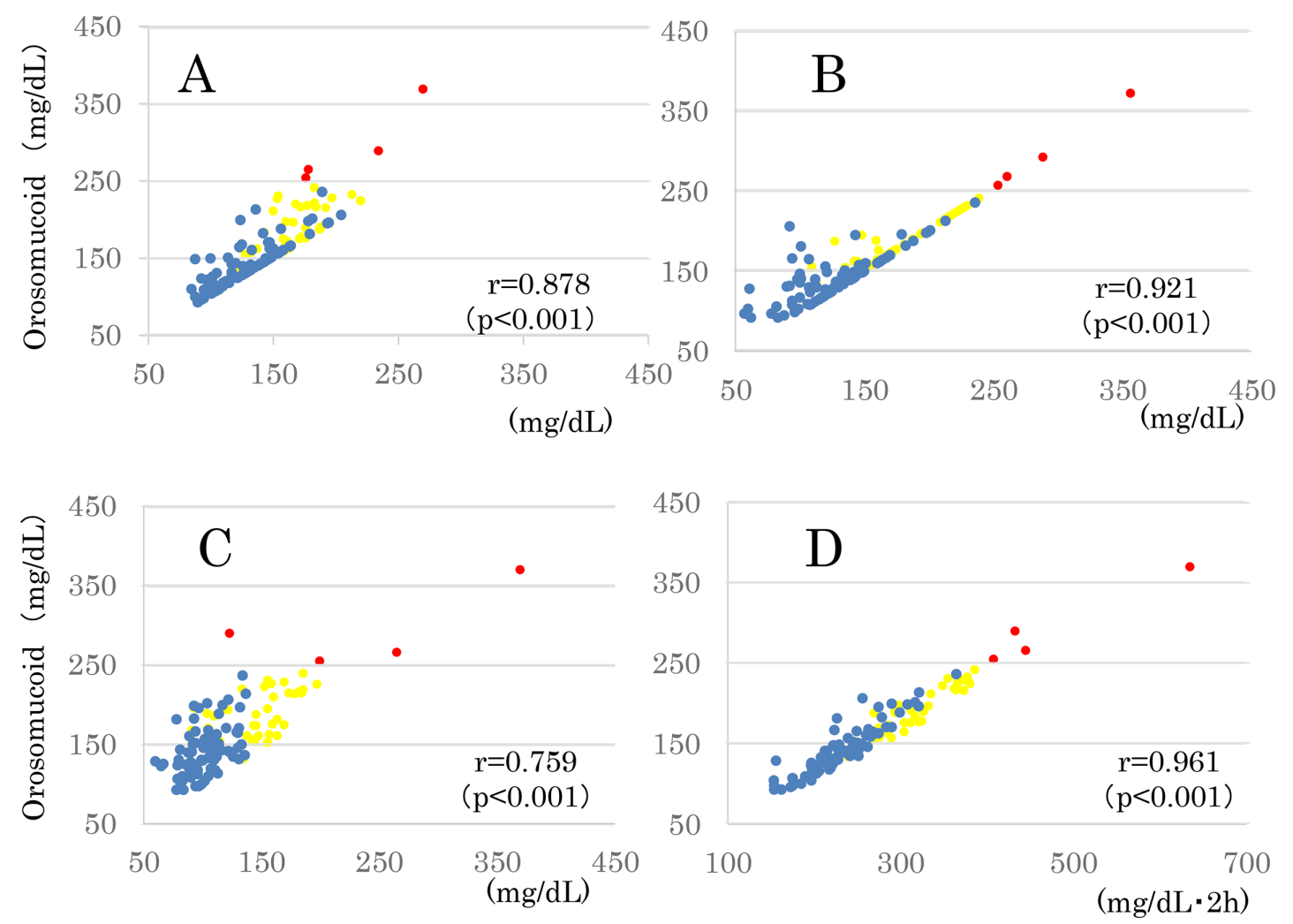

Figure 3 The scatter plot between serum orosomucoid and plasma glucose at $30 \mathrm{~min}(\mathrm{~A}), 1 \mathrm{hour}(\mathrm{B})$ and $2 \mathrm{hours}(\mathrm{C})$ and the area under the glucose curve (D) during a $75 \mathrm{~g}$ oral glucose tolerance test. Blue, yellow and red circles represent normal glucose tolerance, prediabetes and newly identified type 2 diabetes, respectively.

ORM is one of the major acute-phase proteins of glycoprotein acetyls (GlycA), which has been shown to be a risk of incident type 2 diabetes. ${ }^{31}$ Fizelova $e t a l^{32}$ investigated the association of hsCRP and GlycA with insulin secretion, insulin sensitivity, insulin resistance-related traits, and glucose levels. They found that GlycA was a strong predictor of an increase in glycemia (FPG, 2 hours PG, and AUCg) and a decrease in insulin secretion. These observations may be in line with the current finding that elevated circulating ORM and reduced glucose induced insulin secretion were evident in Japanese middle-aged adults with prediabetes. We have previously demonstrated that elevated ORM was associated with postload hyperglycemia in Japanese women (aged 20 years) with NGT, ${ }^{20}$ some of whom were daughters of middle-aged people (aged 50 years) in the present study. These observations suggest that ORM-associated subtle hyperglycemia for decades may be related to reduced glucose induced insulin secretion in middle-aged Japanese people with prediabetes, suggesting glucotoxicity on $\beta$-cells. ${ }^{33}$

The strengths of the present study include a homogeneous study population with scarce confounding factors ${ }^{24}$ and accurate and reliable measures of body composition by DXA. The deduction from the results of family members (daughters in this case) appear to be unique in reducing confounding factors for insulin sensitivity including genetic, dietary, educational and socioeconomic factors. ${ }^{34}$ Several limitations of this study warrant consideration. The small sample size is the major limitation. The cross-sectional design of the present study complicates the drawing of causal inferences, and a single measurement of biochemical variables may be susceptible to short-term variation, which would bias the results toward the null. We used crude measures of insulin sensitivity in muscle and adipose tissue, which may be less accurate. Statistical power was not calculated. As we studied Japanese only, results may not be generalized to other races or ethnicities.

In conclusion, higher circulating ORM and reduced glucose induced insulin secretion were evident in nonobese middle-aged Japanese subjects with prediabetes independently of general and abdominal adiposity and insulin resistance. It is suggested that subtle but chronic (for decades) hyperglycemia associated with elevated circulating ORM may be related to reduced glucose induced insulin secretion.

\section{Author affiliations}

${ }^{1}$ Research Institute for Nutrition Sciences, Mukogawa Joshi Daigaku, Nishinomiya, Japan

${ }^{2}$ Department of Nutrition, Osaka City Juso Hospital, Osaka, Japan

${ }^{3}$ Department of Public Health, Shiga University of Medical Science, Otsu, Japan ${ }^{4}$ Laboratory of Community Health and Nutrition, Department of Bioscience, Graduate School of Agriculture, Ehime University, Matsuyama, Japan

${ }^{5}$ Open Research Center for Studying of Lifestyle-Related Diseases, Mukogawa Joshi Daigaku, Nishinomiya, Japan

${ }^{6}$ Department of Health, Sports, and Nutrition, Faculty of Health and Welfare, Kobe Women's University, Kobe, Japan

${ }^{7}$ Department of Food Sciences and Nutrition, Mukogawa Joshi Daigaku, Nishinomiya, Japan 
${ }^{8}$ Department of Endocrinology, First Affiliated Hospital of Kunming Medical University, Kunming, China

${ }^{9}$ Department of Medicine, Kohnan Kakogawa Hospital, Kakogawa, Japan

Acknowledgements The authors thank all participants for their dedicated and conscientious collaboration.

Contributors AT, KK, MY, MT, SM-I, MH, MK and BW collected and analyzed data. TK wrote the manuscript, and KF reviewed and edited it. All authors approved the final version of the manuscript to be published. TK supervised the study, had full access to all the data in the study and takes responsibility for the integrity of the data and the accuracy of the data analysis.

Funding The authors have not declared a specific grant for this research from any funding agency in the public, commercial or not-for-profit sectors.

Competing interests None declared.

Patient consent for publication Not required

Ethics approval The study was approved by the Mukogawa Women's University Ethical Committee (No. 07-28 on February 19, 2008).

Provenance and peer review Not commissioned; externally peer reviewed.

Data availability statement All data relevant to the study are included in the article or uploaded as supplemental information. The ethical committee of the University does not allow us to open data except for a manuscript.

Supplemental material This content has been supplied by the author(s). It has not been vetted by BMJ Publishing Group Limited (BMJ) and may not have been peer-reviewed. Any opinions or recommendations discussed are solely those of the author(s) and are not endorsed by BMJ. BMJ disclaims all liability and responsibility arising from any reliance placed on the content. Where the content includes any translated material, BMJ does not warrant the accuracy and reliability of the translations (including but not limited to local regulations, clinical guidelines, terminology, drug names and drug dosages), and is not responsible for any error and/or omissions arising from translation and adaptation or otherwise.

Open access This is an open access article distributed in accordance with the Creative Commons Attribution Non Commercial (CC BY-NC 4.0) license, which permits others to distribute, remix, adapt, build upon this work non-commercially, and license their derivative works on different terms, provided the original work is properly cited, appropriate credit is given, any changes made indicated, and the use is non-commercial. See: http://creativecommons.org/licenses/by-nc/4.0/.

ORCID iD

Tsutomu Kazumi http://orcid.org/0000-0002-8855-9268

\section{REFERENCES}

1 Hotamisligil GS. Inflammation and metabolic disorders. Nature 2006;444:860-7.

2 Lusis AJ. Atherosclerosis. Nature 2000;407:233-41.

3 Vistisen D, Witte DR, Brunner EJ, et al. Risk of cardiovascular disease and death in individuals with prediabetes defined by different criteria: the Whitehall II study. Diabetes Care 2018;41:899-906.

4 Beulens J, Rutters F, Rydén L, et al. Risk and management of prediabetes. Eur J Prev Cardiol 2019;26:47-54.

5 Colak A, Akinci B, Diniz G, et al. Postload hyperglycemia is associated with increased subclinical inflammation in patients with prediabetes. Scand J Clin Lab Invest 2013;73:422-7.

6 Guerrero-Romero F, Simental-Mendía LE, Rodríguez-Morán M. Association of C-reactive protein levels with fasting and postload glucose levels according to glucose tolerance status. Arch Med Res 2014:45:70-5

7 Wu J, Liang Z, Zhou J, et al. Association of biomarkers of inflammation and endothelial dysfunction with fasting and postload glucose metabolism: a population-based prospective cohort study among inner Mongolians in China. Can J Diabetes 2016;40:509-14.

8 Doi Y, Kiyohara Y, Kubo M, et al. Relationship between C-reactive protein and glucose levels in community-dwelling subjects without diabetes: the Hisayama study. Diabetes Care 2005;28:1211-3.

9 Grossmann V, Schmitt VH, Zeller T, et al. Profile of the immune and inflammatory response in individuals with prediabetes and type 2 diabetes. Diabetes Care 2015;38:1356-64.

10 Wang X, Bao W, Liu J, et al. Inflammatory markers and risk of type 2 diabetes: a systematic review and meta-analysis. Diabetes Care 2013;36:166-75.
11 Doi Y, Kiyohara Y, Kubo M, et al. Elevated C-reactive protein is a predictor of the development of diabetes in a general Japanese population: the Hisayama study. Diabetes Care 2005;28:2497-500.

12 Nakanishi S, Yamane K, Kamei N, et al. Elevated C-reactive protein is a risk factor for the development of type 2 diabetes in Japanese Americans. Diabetes Care 2003;26:2754-7.

13 Bao X, Borné Y, Johnson L, et al. Comparing the inflammatory profiles for incidence of diabetes mellitus and cardiovascular diseases: a prospective study exploring the 'common soil' hypothesis. Cardiovasc Diabetol 2018;17:87.

14 Kanmani S, Kwon M, Shin M-K, et al. Association of C-reactive protein with risk of developing type 2 diabetes mellitus, and role of obesity and hypertension: a large population-based Korean cohort study. Sci Rep 2019;9:4573.

15 Luo Z, Lei H, Sun Y, et al. Orosomucoid, an acute response protein with multiple modulating activities. $J$ Physiol Biochem 2015;71:329-40.

16 Duncan BB, Schmidt MI, Pankow JS, et al. Low-Grade systemic inflammation and the development of type 2 diabetes: the Atherosclerosis risk in Communities study. Diabetes 2003;52:1799-805.

17 Schmidt MI, Duncan BB, Sharrett AR, et al. Markers of inflammation and prediction of diabetes mellitus in adults (atherosclerosis risk in Communities study): a cohort study. Lancet 1999;353:1649-52.

18 Muhammad IF, Borné Y, Hedblad B, et al. Acute-Phase protein and incidence of diabetes: a population-based cohort study. Acta Diabetol 2016;53:981-9.

19 Würtz P, Tiainen M, Mäkinen V-P, et al. Circulating metabolite predictors of glycemia in middle-aged men and women. Diabetes Care 2012;35:1749-56.

20 Tsuboi A, Minato S, Yano M, et al. Association of serum orosomucoid with 30-min plasma glucose and glucose excursion during oral glucose tolerance tests in non-obese young Japanese women. BMJ Open Diabetes Res Care 2018;6:e000508.

21 Tsuboi A, Kitaoka K, Yano M, et al. Higher circulating orosomucoid and lower early-phase insulin secretion in midlife Japanese with slower glucose disposal during oral glucose tolerance tests. Diabetol Int 2020;11:27-32.

22 Wu B, Huang J, Fukuo K, et al. Different associations of trunk and lower-body fat mass distribution with cardiometabolic risk factors between healthy middle-aged men and women. Int J Endocrinol 2018;2018:1-10.

23 American Diabetes Association. 2. Classification and Diagnosis of Diabetes: Standards of Medical Care in Diabetes-2018. Diabetes Care 2018;41:S13-27.

24 Tanaka M, Yoshida T, Bin W, et al. FTO, abdominal adiposity, fasting hyperglycemia associated with elevated $\mathrm{HbA} 1 \mathrm{c}$ in Japanese middleaged women. $J$ Atheroscler Thromb 2012;19:633-42.

25 Stumvoll M, Mitrakou A, Pimenta W, et al. Use of the oral glucose tolerance test to assess insulin release and insulin sensitivity. Diabetes Care 2000;23:295-301.

26 Matthews DR, Hosker JP, Rudenski AS, et al. Homeostasis model assessment: insulin resistance and beta-cell function from fasting plasma glucose and insulin concentrations in man. Diabetologia 1985;28:412-9.

27 Matsuda M, DeFronzo RA. Insulin sensitivity indices obtained from oral glucose tolerance testing: comparison with the euglycemic insulin clamp. Diabetes Care 1999;22:1462-70.

28 Lim U, Turner SD, Franke AA, et al. Predicting total, abdominal, visceral and hepatic adiposity with circulating biomarkers in Caucasian and Japanese American women. PLoS One 2012;7:e43502.

29 Pickup JC, Mattock MB, Chusney GD, et al. NIDDM as a disease of the innate immune system: association of acute-phase reactants and interleukin-6 with metabolic syndrome X. Diabetologia 1997:40:1286-92.

30 McMillan DE. Increased levels of acute-phase serum proteins in diabetes. Metabolism 1989;38:1042-6.

31 Connelly MA, Gruppen EG, Wolak-Dinsmore J, et al. GlycA, a marker of acute phase glycoproteins, and the risk of incident type 2 diabetes mellitus: PREVEND study. Clin Chim Acta 2016;452:10-17.

32 Fizelova M, Jauhiainen R, Kangas AJ, et al. Differential associations of inflammatory markers with insulin sensitivity and secretion: the prospective METSIM study. J Clin Endocrinol Metab 2017;102:3600-9.

33 Weir GC. Glucolipotoxicity, $\beta$-cells, and diabetes: the emperor has no clothes. Diabetes 2020;69:273-8.

34 Volaco A, Cavalcanti AM, Filho RP, et al. Socioeconomic status: the missing link between obesity and diabetes mellitus? Curr Diabetes Rev 2018;14:321-6. 